\title{
Effect of Stator Winding Faults on Performance Characteristics of Three Phase Induction Motor (TPIM)
}

\author{
D. K. Chaturvedi \\ SMIEEE \\ Dept. of Electrical Engineering, \\ Faculty of Engineering, \\ D.E.I., Dayalbagh, \\ Agra, India.
}

\author{
Mayank Pratap Singh \\ Dept. of Electrical Engineering, \\ Faculty of Engineering, D.E.I., \\ Dayalbagh, Agra, India.
}

\begin{abstract}
To carry out the induction machine analysis under dynamic, transient and steady state conditions, the analytical techniques are used to simulate the TPIM. Here, the Park's transformation is used to transform balanced $3-\Phi$ currents $i_{a}, i_{b}$, and $i_{c}$ to balanced 2- $\Phi$ currents $i_{\alpha,}$ and $i_{\beta}$ to accurately model the TPIM. In this paper, an accurate mathematical model is developed for induction motor and the effect of stator winding faults (like one, two or all three phase winding(s) short circuited by 10\%, 20\%, 30\% and 40\%) on its performance characteristics have been studied under different operating conditions.
\end{abstract}

\section{Keywords}

induction motor modelling, motor characteristics, motor faults, park's transformation.

\section{INTRODUCTION}

The TPIM are one of the most widely used and popular drive in the world to rotate mechanical loads due to its inherent features such as compact, robust and no repair maintenance during its life time. After the advancement of power electronics, the limitation of induction motor for precise control of torque speed characteristic also overruled. For accurate control of induction motors, it is necessary to have very good mathematical model and must aware about its various performance characteristics [1-4].

In these paper, the TPIM is modeled mathematically and simulated using Matlab under different stator fault conditions and drawn the performance characteristics. The paper is divided in four sections. The first section deals with the brief introduction, followed by mathematical modeling in section II. The third section discusses the simulation of TPIM under different fault conditions and compared the results with healthy motor. Finally, the work is concluded.

\section{MATHEMATICAL MODELING OF TPIM}

The stator and rotor windings carry alternating currents in three phase induction machines. The flux produced by stator coils rotates at fixed speed $\left(\omega_{\mathrm{s}}\right)$ compared to frame of reference. This flux links the rotor coil and a current is induced which is responsible for MMF that also rotates at $\omega_{\mathrm{s}}$ compared to frame of reference as shown in Fig. 1.

Therefore, relative speed between stator and rotor fields is zero under stable conditions. For carrying out the induction machine analysis under dynamic, transient and steady state conditions, we develop the analytical techniques. Here, the transformation from balanced three phase currents $i_{a} i_{b}, i_{c}$ to balanced two phase currents $i_{\alpha,} i_{\beta}$ was obtained. The quality of the MMF produced by two phase currents was identical with that produced by three phase currents. Further, the transformations were so chosen as to make the impedance per phase, same both for two phase and three phase induction machines. Thus the constants per phase to be used in the equivalent two phase induction machine analysis.

Examinations reveals that phase $\boldsymbol{a}$-axis of three phase machine coincides with phase $\alpha$-axis or phase $d$-axis of two phase machines. In view of this, the results obtained for d-axis quantities apply equally well to the $\alpha$-phase of the two phase machines or $\boldsymbol{a}$-phase of three phase machine.

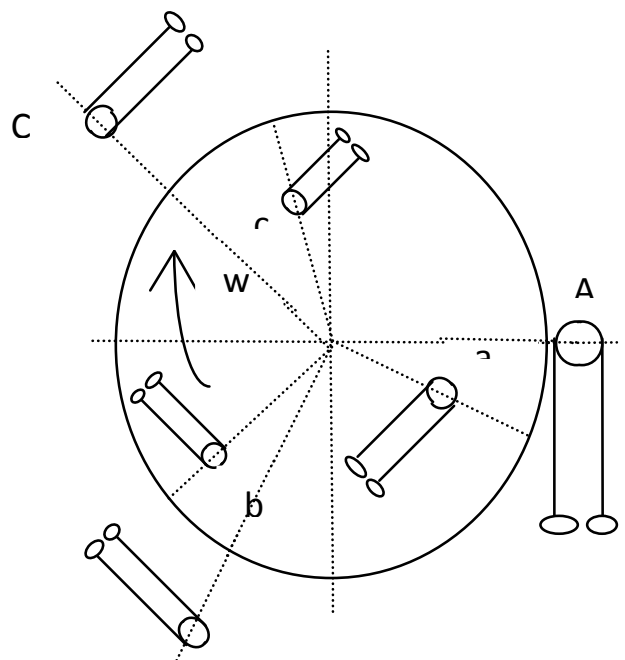

B

Fig. 1 Schematic Diagram of TPIM

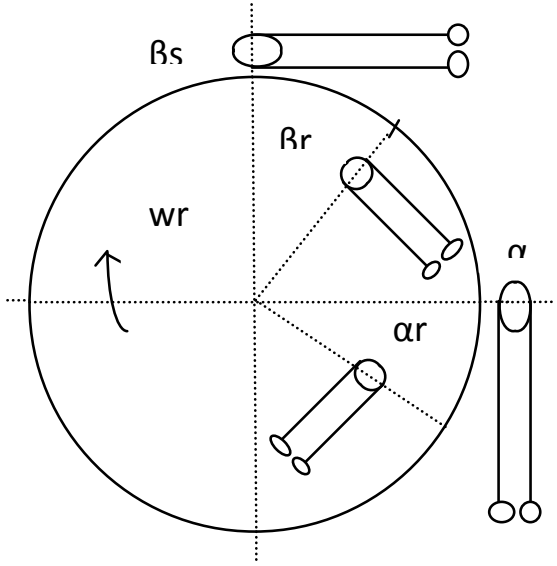

Fig. 2 TPIM equivalent two phase induction motor 
The conversion of three phase stator winding to two phase stator winding is given in equation (1).

$$
\left[\begin{array}{l}
i_{\alpha s} \\
i_{\beta s} \\
i_{o s}
\end{array}\right]=\sqrt{\frac{2}{3}}\left[\begin{array}{ccc}
1 & -\frac{1}{2} & -\frac{1}{2} \\
0 & -\frac{\sqrt{3}}{2} & -\frac{\sqrt{3}}{2} \\
-\frac{1}{\sqrt{2}} & \frac{1}{\sqrt{2}} & \frac{1}{\sqrt{2}}
\end{array}\right]\left[\begin{array}{l}
i_{A} \\
i_{B} \\
i_{C}
\end{array}\right]
$$

The conversion from two phase stator winding to d-q axes winding is

$$
\left[\begin{array}{l}
i_{d s} \\
i_{q s}
\end{array}\right]=\left[\begin{array}{ll}
1 & 0 \\
0 & 1
\end{array}\right]\left[\begin{array}{l}
i_{\alpha s} \\
i_{\beta s}
\end{array}\right]
$$

For rotor, three phase $(\mathrm{a}, \mathrm{b}$, and $\mathrm{c})$ to two phase $(\alpha$ and $\beta$ ) conversion requires no change of space frame, because both are on the rotating member.

$$
\left[\begin{array}{l}
i_{\alpha r} \\
i_{\beta r} \\
i_{o r}
\end{array}\right]=\sqrt{\frac{2}{3}}\left[\begin{array}{ccc}
1 & -\frac{1}{2} & -\frac{1}{2} \\
0 & -\frac{\sqrt{3}}{2} & -\frac{\sqrt{3}}{2} \\
-\frac{1}{\sqrt{2}} & \frac{1}{\sqrt{2}} & \frac{1}{\sqrt{2}}
\end{array}\right]\left[\begin{array}{l}
i_{a} \\
i_{b} \\
i_{c}
\end{array}\right]
$$

For the rotor, the transformation from $\alpha-\beta$ to $d-q$ axes involves the change from rotating $\alpha-\beta$ axes to pseudo-stationary $d-q$ axes winding as shown in Fig. 3 .

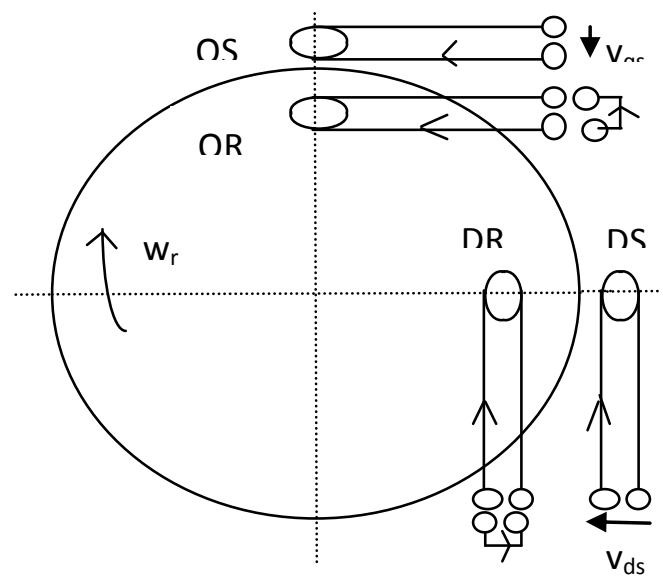

Fig. 3 Equivalent d-q axes model of TPIM

$\left[\begin{array}{l}I_{d r} \\ I_{q r}\end{array}\right]=\left[\begin{array}{cc}\cos (\theta) & \sin (\theta) \\ -\sin (\theta) & \cos (\theta)\end{array}\right]\left[\begin{array}{l}i_{\alpha r} \\ i_{\beta r}\end{array}\right]$

Here $\boldsymbol{\theta}$ is the variable angle which the rotating $\boldsymbol{\alpha}-\boldsymbol{\beta}$ windings make with stationary $\boldsymbol{d} \boldsymbol{- q}$ axes winding. The frequency of the currents in three phase rotor winding $\boldsymbol{a}, \boldsymbol{b}, \boldsymbol{c}$ or in two phase rotor windings $\boldsymbol{\alpha}_{\mathbf{r}}, \boldsymbol{\beta}_{\mathbf{r}}$ is slip frequency $\boldsymbol{s} \boldsymbol{f}$. Since the $\boldsymbol{d}-\boldsymbol{q}$ axes windings are stationary, the frequency of currents in $d_{r}, q_{r}$ windings is the line frequency $f$.

\section{Electrical Performance Equations}

The generalized mathematical model for poly-phase induction machine requires four coils. Two coils DS and QS on the stator represent poly-phase stator windings of both three phase and two phase induction machines. Two coils DR and QR on the rotor represent the wound rotor as well as the squirrel cage rotor. For cage rotor machines, the two coils DR and QR may be thought of as equivalent to all the squirrel cage bars.

The general voltage equations are:

$\left[\begin{array}{c}v_{d s} \\ v_{q s} \\ v_{d r} \\ v_{q r}\end{array}\right]=\left[\begin{array}{cccc}r_{d s}+L_{d s} p & 0 & M_{d} p & 0 \\ 0 & r_{q s}+L_{q s} p & 0 & M_{q} p \\ M_{d} p & -M_{q} w_{r} & r_{d r}+L_{d r} p & -L_{q r} w_{r} \\ M_{d} w_{r} & M_{q} p & L_{d r} w_{r} & r_{q r}+L_{q r} p\end{array}\right]\left[\begin{array}{l}i_{d s} \\ i_{q s} \\ i_{d r} \\ i_{q r}\end{array}\right]$

The knowledge of the induction machine construction gives the various constraints are as follows:

Stator and rotor both have balanced winding configuration

$$
\begin{aligned}
& r_{d s}=r_{q s}=r_{s} \text { resistance of each stator coil and } \\
& r_{d r}=r_{q r}=r_{r} \text { resistance of each rotor coil }
\end{aligned}
$$

The air gap is uniform, thus

$\mathrm{L}_{\mathrm{ds}}=\mathrm{L}_{\mathrm{qs}}=\mathrm{L}_{\mathrm{s}}=$ self inductance of each stator coil and

$$
\mathrm{L}_{\mathrm{dr}}=\mathrm{L}_{\mathrm{qr}}=\mathrm{L}_{\mathrm{r}}=\text { self inductance of each rotor coil }
$$

Coils DS, DR and QS, QR are identical

$\mathrm{M}_{\mathrm{d}}=\mathrm{M}_{\mathrm{q}}=\mathrm{M}$

Further rotor windings are short circuited, therefore $\mathrm{v}_{\mathrm{a}}=\mathrm{v}_{\mathrm{b}}$ $=v_{c}=0$, for three phase rotor winding and $\mathrm{v}_{\alpha}=\mathrm{v}_{\beta}=0$ for two phase rotor winding. Now voltages $\mathrm{v}_{\mathrm{dr}}, \mathrm{v}_{\mathrm{qr}}$ are given in terms of $\mathrm{v}_{\alpha}$ and $\mathrm{v}_{\beta}$ and in terms of $\mathrm{v}_{\mathrm{a}}, \mathrm{v}_{\mathrm{b}}$, and $\mathrm{v}_{\mathrm{c}}$. Since $\mathrm{v}_{\mathrm{a}}=\mathrm{v}_{\mathrm{b}}=\mathrm{v}_{\mathrm{c}}=0$ and $\mathrm{v}_{\alpha}=\mathrm{v}_{\beta}=0$, the coil voltages $\mathrm{v}_{\mathrm{dr}}, \mathrm{v}_{\mathrm{qr}}$ are also equal to zero, i.e. $\mathrm{v}_{\mathrm{dr}}=\mathrm{v}_{\mathrm{qr}}=0$ as given in equation (6).

$$
\left[\begin{array}{c}
v_{d s} \\
v_{d s} \\
0 \\
0
\end{array}\right]=\left[\begin{array}{cccc}
r_{s}+L_{s} p & 0 & -M p & 0 \\
0 & r_{s}+L_{s} p & 0 & -M p \\
M p & -M w_{r} & -\left(r_{r}+L_{r} p\right) & L_{r} w_{r} \\
M w_{r} & M p & -L_{r} w_{r} & -\left(r_{r}+L_{r} p\right)
\end{array}\right]\left[\begin{array}{c}
i_{d s} \\
i_{q s} \\
i_{d r} \\
i_{q r}
\end{array}\right]
$$

The negative sign before $\mathrm{i}_{\mathrm{dr}}$ and $\mathrm{i}_{\mathrm{qr}}$ has been taken into consideration in the corresponding columns. The electromagnetic torque at any instant is obtained from equation (7).

$$
\mathrm{T}_{\mathrm{e}}=\mathrm{M}\left(\mathrm{i}_{\mathrm{ds}} \mathrm{i}_{\mathrm{qr}}-\mathrm{i}_{\mathrm{dr}} \mathrm{i}_{\mathrm{qs}}\right) \text {------------(7) }
$$

\section{SIMULATION OF TPIM MODEL}

The Simulink model of TPIM has been developed using above equations as shown in Fig. 4.

\section{a. Simulation of Healthy TPIM}

The TPIM model simulated under healthy conditions and the transient and steady state performance of induction motor is shown in Figs. 5-7. 


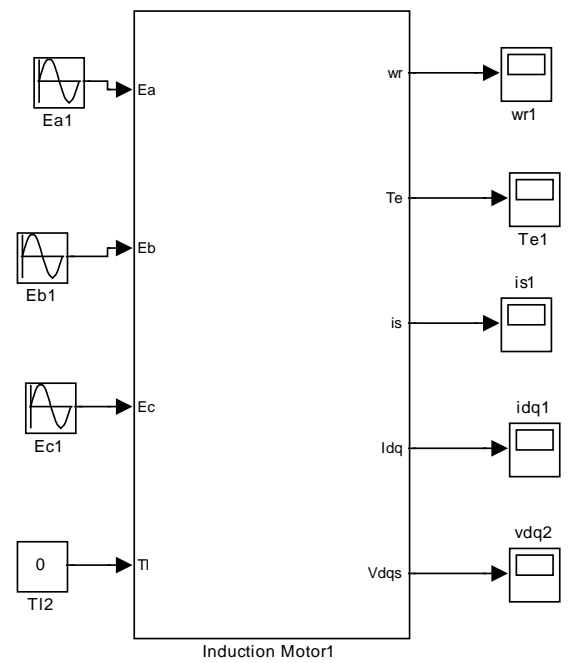

Fig. 4 Simulink model of TPIM

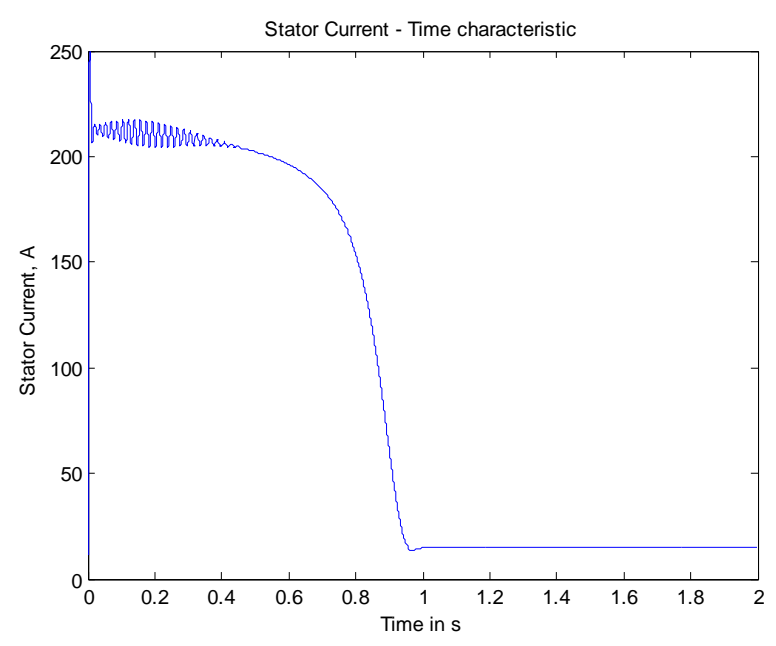

Fig. 5 Stator current transients of TPIM

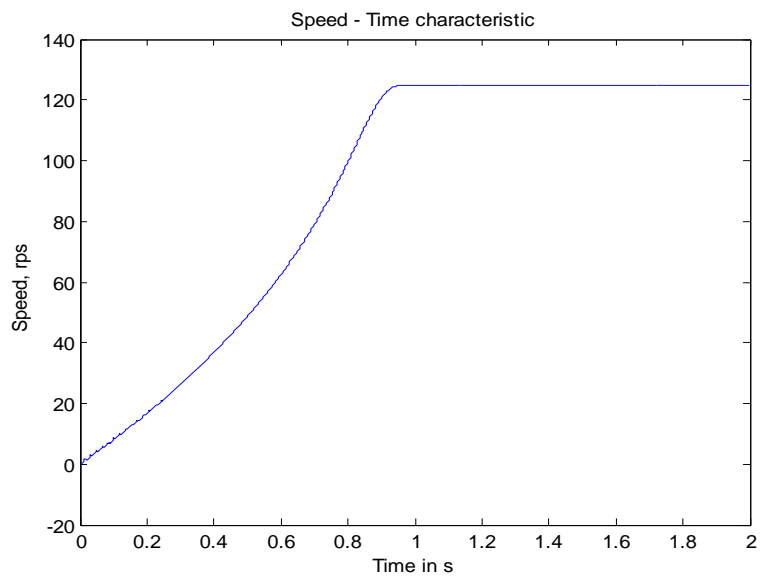

Fig. 6 Transient Speed Curve of TPIM

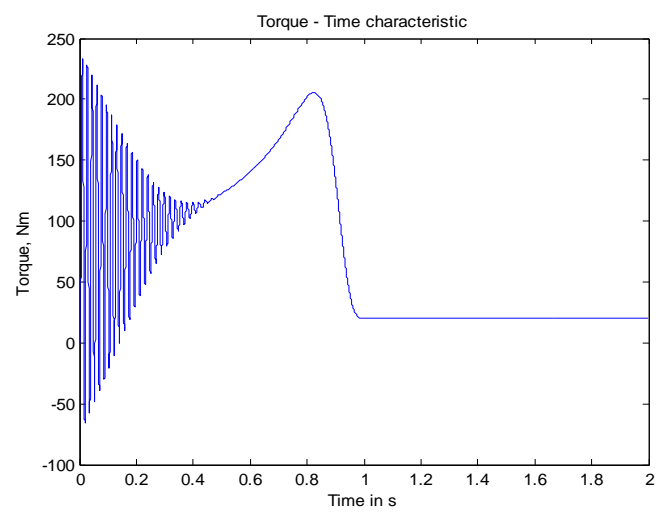

Fig. 7 Transient Torque Curve of TPIM

b. TPIM Simulation under different stator faults

\section{i. One Phase Short Circuited}

The effect of $\boldsymbol{a}$-phase winding which is short circuited by $10 \%, 20 \%, 30 \%, 40 \%$ and other phase windings are healthy is shown in Fig. 8.

The Fig. 8 (a) shows the developed motor torque with respect to speed. It is clear from the results obtained that during starting the developed motor torque has significant changes but in running condition, the developed motor torque has no significant changes as shown in Fig. This is due to no change in the loading conditions of TPIM and the output power of TPIM will remain same.

The input power slightly change during starting when the Phase ' $\boldsymbol{a}$ ' winding gets short circuited. Hence, there is slight change in the efficiency during starting, but under running conditions efficiency is almost same as shown in Fig. 8(b).

The short circuit effect of phase ' $\boldsymbol{a}$ ' on power factors with respect to speed is shown in Fig. 8(c). There is a change in power factor of phase- ' $\boldsymbol{a}$ ' shown in Fig. as phase resistance and reactance vary with the percentage of short circuited portion of the winding.

During starting, there is slight change in output power but in running condition there is no significant change in output power as shown in Fig. 8(d).

Fig. 8(e) represents the current drawn by the motor in phase $\boldsymbol{a}$ increases when the amount of winding short circuited will increase, but no effect on phase $\boldsymbol{b}$ and $\boldsymbol{c}$ current as these are the healthy phase windings.

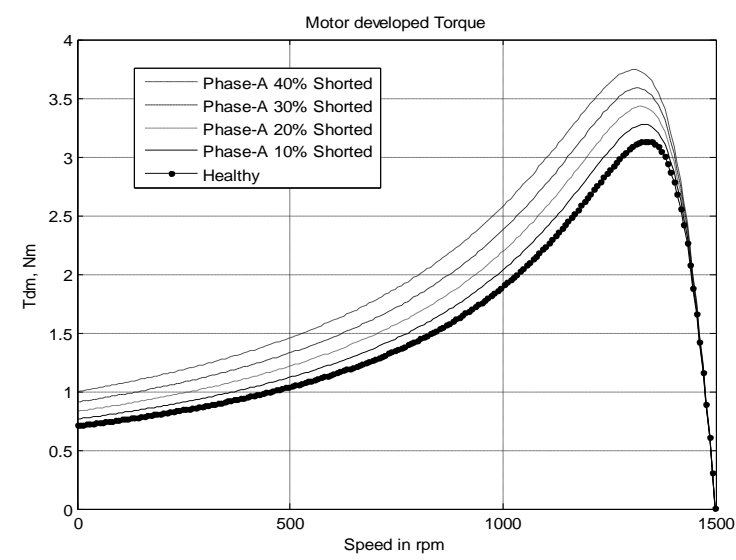

(a) Developed motor torque with respect to speed 


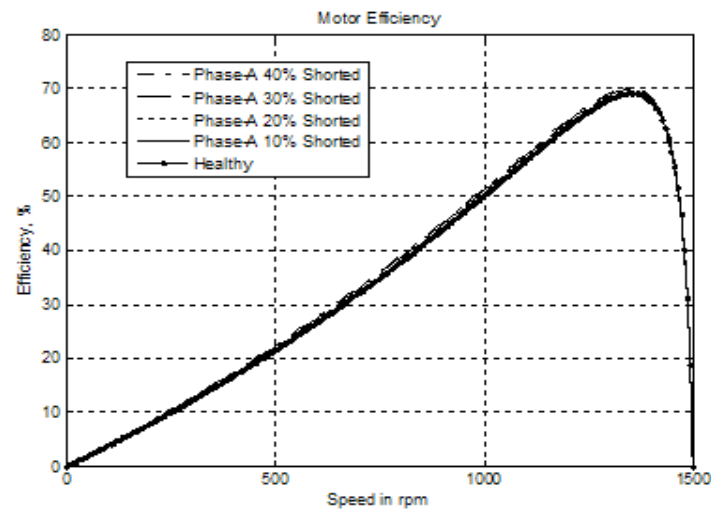

(b) Efficiency with respect to speed

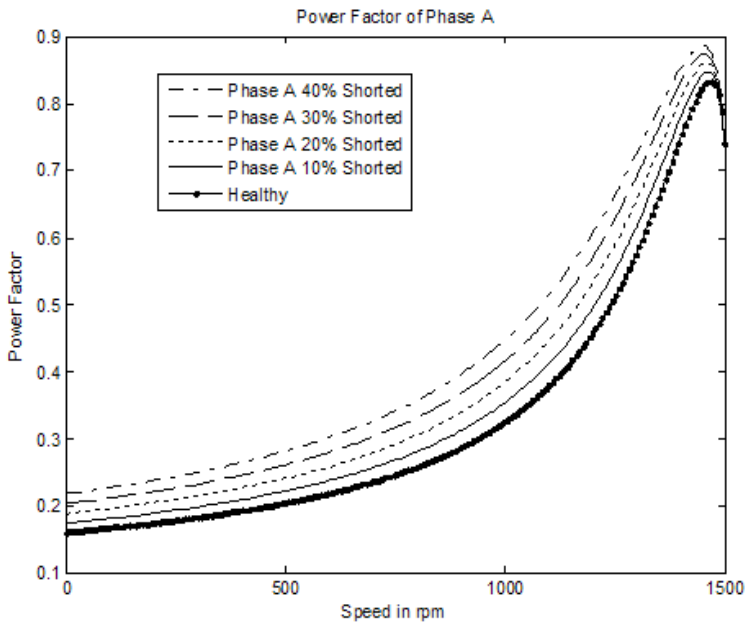

(c) Power factor of phase $a$ Vs speed

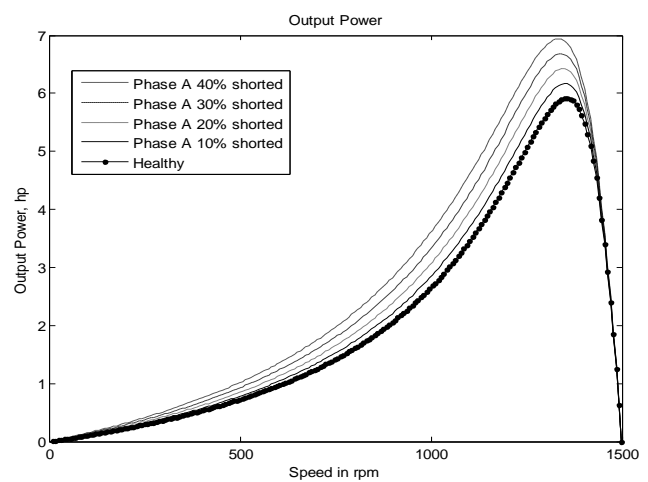

(d) Output Power with respect to speed

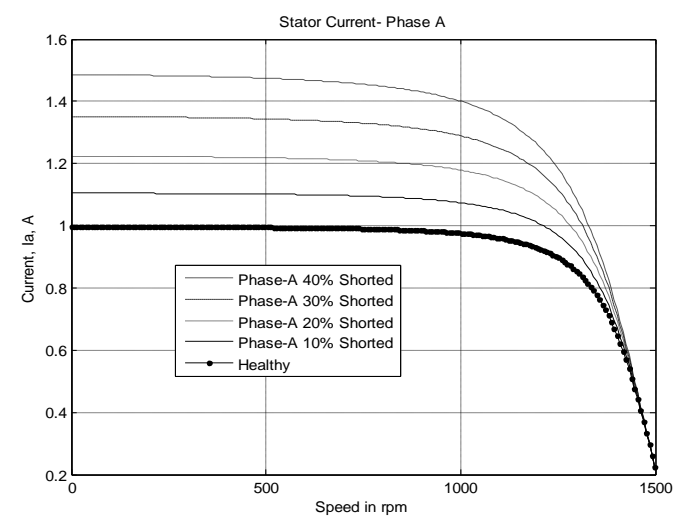

(e) stator current of phase $a$ with respect to speed

Fig. 8 Effect of $a$ - phase winding which is short circuited by $10 \%, 20 \%, 30 \%, 40 \%$ on motor performance

\section{ii. Two Phase Short Circuited}

The effect of $\boldsymbol{a}$ - phase and $\boldsymbol{b}$-phase windings which are short circuited by $10 \%, 20 \%, 30 \%, 40 \%$ and phase $\mathrm{c}$ is healthy on TPIM performance characteristics are shown in Fig. 9.

The Fig.9(a) shows the developed motor torque with respect to speed. It is clear from the results obtained that during starting the developed motor torque has significant changes but in running condition, the developed motor torque has no significant changes as shown in Fig. This is due to no change in the loading conditions of TPIM and the output power of TPIM will remain same.

The input power slightly changes during starting when the Phase ' $\boldsymbol{a}$ ' and Phase ' $\boldsymbol{b}$ ' windings get short circuited. Hence, there is slight change in the efficiency during starting, but under running conditions efficiency is almost same as shown in Fig. 9(b).

The effect of short circuit in Phase ' $\boldsymbol{a}$ ' and Phase ' $\boldsymbol{b}$ ' on the Power factors with respect to speed is shown in Fig. 9(c).

During starting, there is slight change in output power but in running condition there is no significant change in output power as shown in Fig. 9(d).

The motor current in Phases $\boldsymbol{a}$, is shown in Figs. Fig .9(e) which indicates that that the current drawn by the motor in phase $\boldsymbol{a}$ and phase $\boldsymbol{b}$ increase when the amount of windings short circuited, but no effect on phase $c$ current as this is the healthy phase winding.

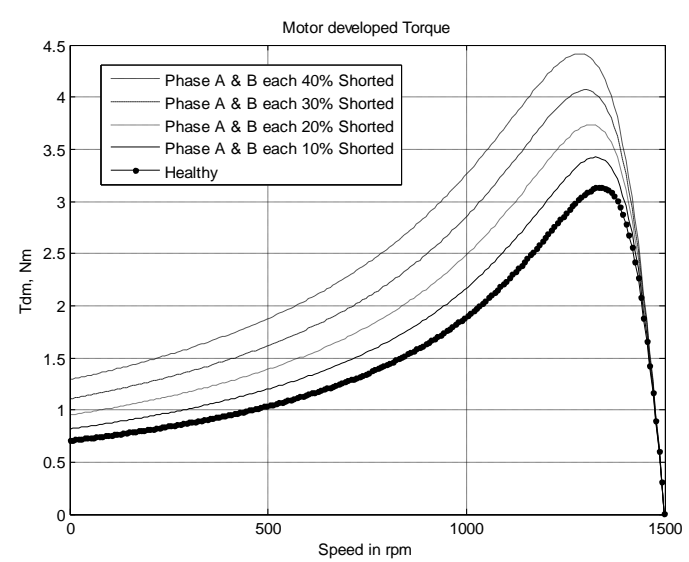

(a) Developed Motor Torque with respect to speed 


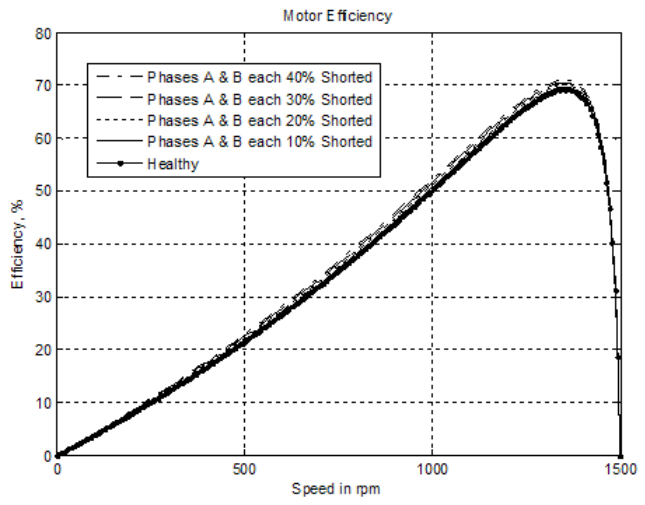

(b) Efficiency with respect to speed

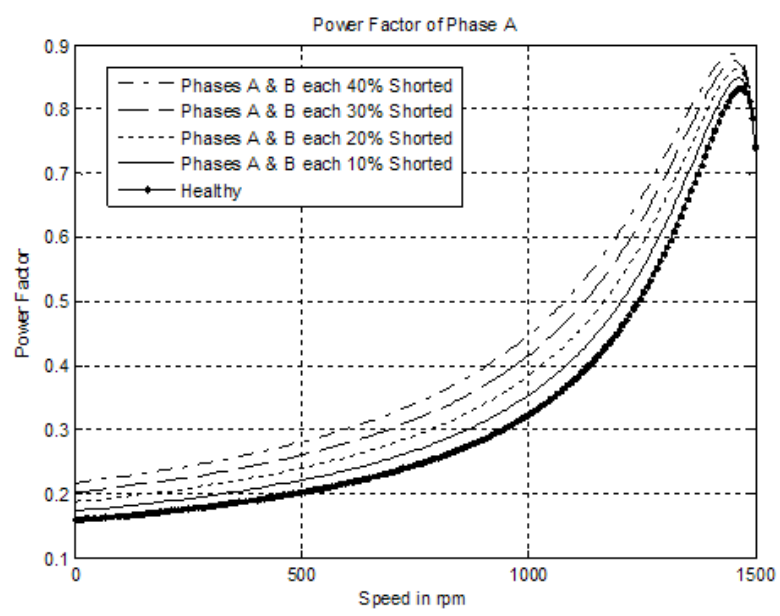

(c) Power factor of phase ' $a$ ' Vs speed

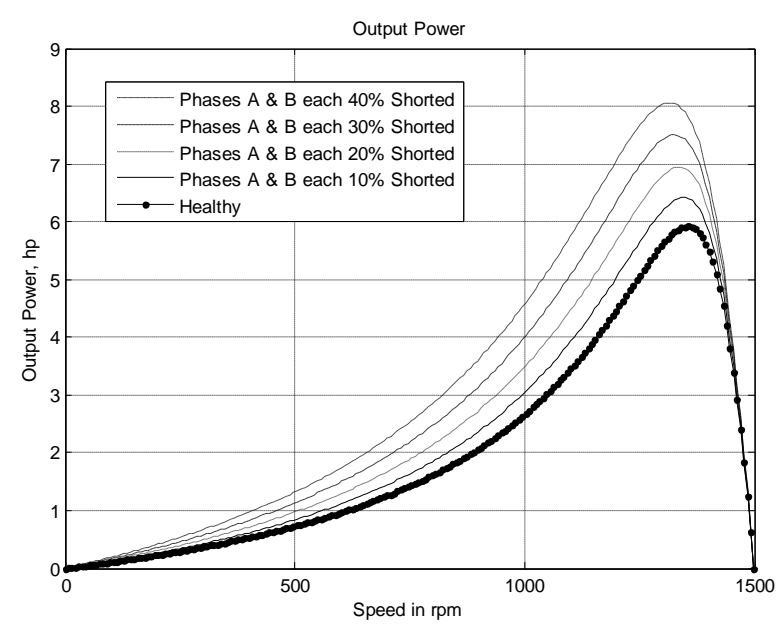

(d) Output Power with respect to speed

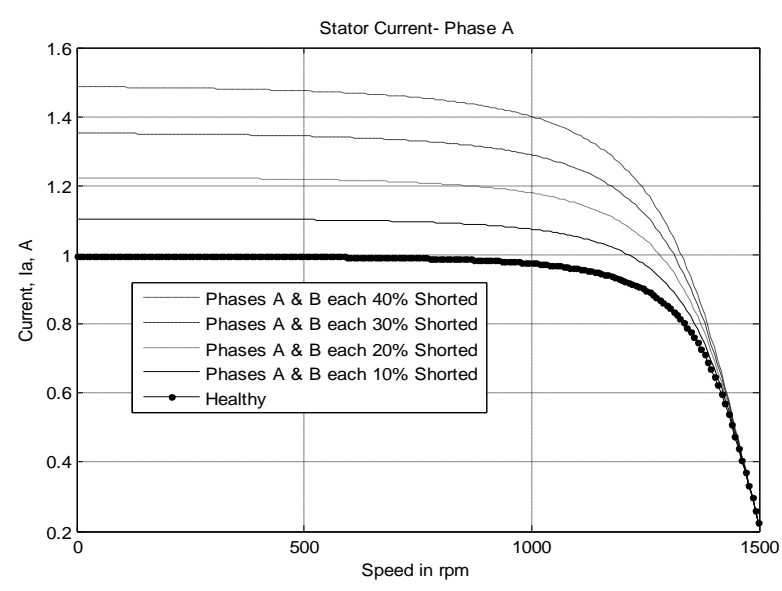

(e) Stator current of Phase ' $a$ ' with respect to speed

Fig. 9 Effect of phases a and $b$ short circuited by $10 \%$, $20 \%, 30 \%, 40 \%$ and phase $c$ is healthy on motor performance

\section{iii. Three Phase Short Circuited}

The effect of Phase ' $\boldsymbol{a}$ ', ' $\boldsymbol{b}$ ' and ' $\boldsymbol{c}$ ' windings short circuited by 10\%, 20\%, 30\%, 40\% are shown in Fig. 10.

The Fig. 10(a) shows the developed motor torque with respect to speed. It is clear from the results obtained that during starting the developed motor torque has significant changes but in running condition, the developed motor torque has no significant changes. This is due to no change in the loading conditions of TPIM and the output power of TPIM will remain same.

There is slight change in the efficiency during starting, but under running conditions efficiency is almost same as shown in Fig. 10(b).

The effect of short circuit in Phase ' $\boldsymbol{a}$ ', Phase ' $\boldsymbol{b}$ ' and Phase ' $c$ ' on the Power factors of phase $\boldsymbol{a}, \boldsymbol{b}$ and $\boldsymbol{c}$ with respect to speed is shown in Fig.10(c).

During starting, there is slight change in output power but in running condition there is no significant change in output power as shown in Fig.10(d).

The motor current increases in all three phases and illustrated in Figs. 10(e).

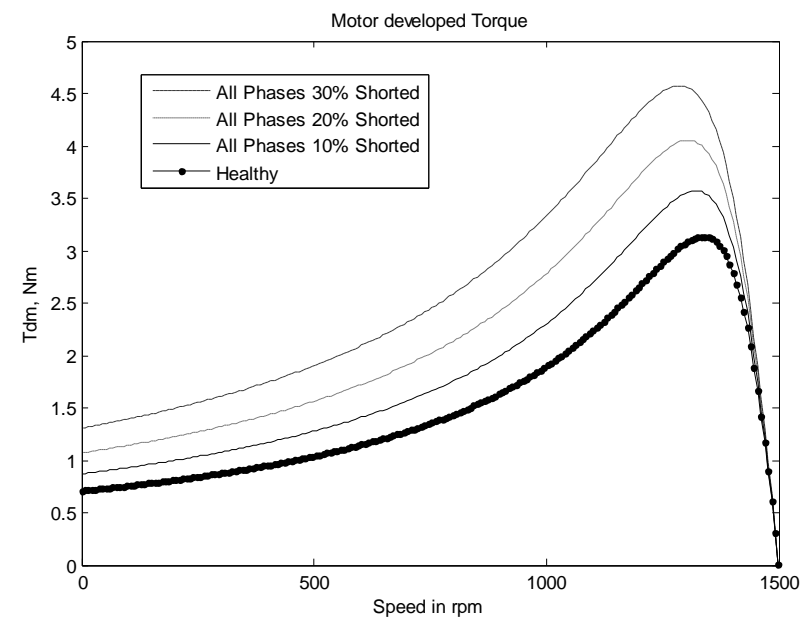

(a) Motor developed Torque with respect to speed 


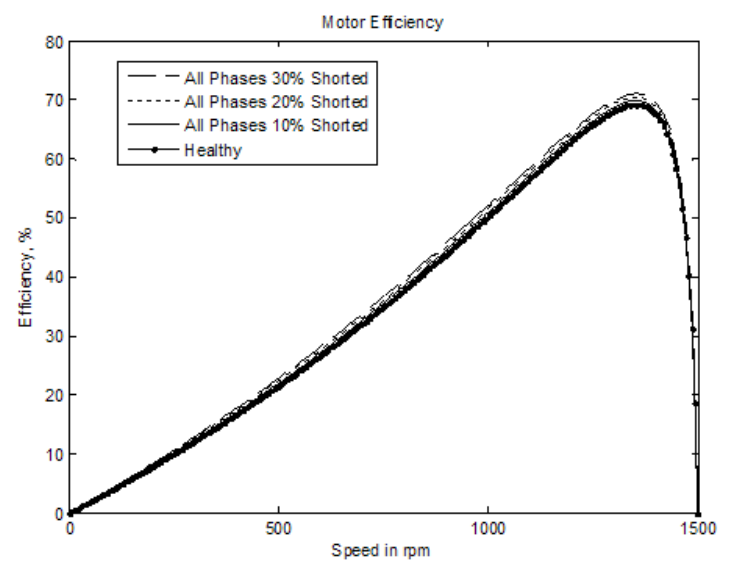

(b) Motor Efficiency with respect to speed

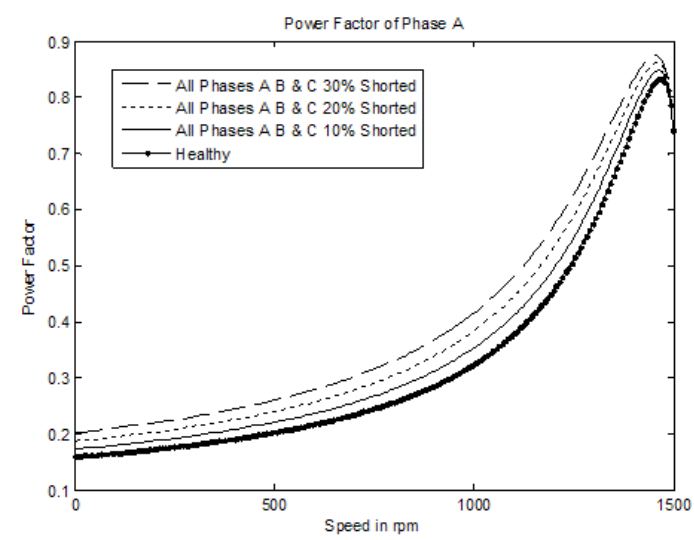

(c) Power Factor of Phase ' $a$ ' with respect to speed

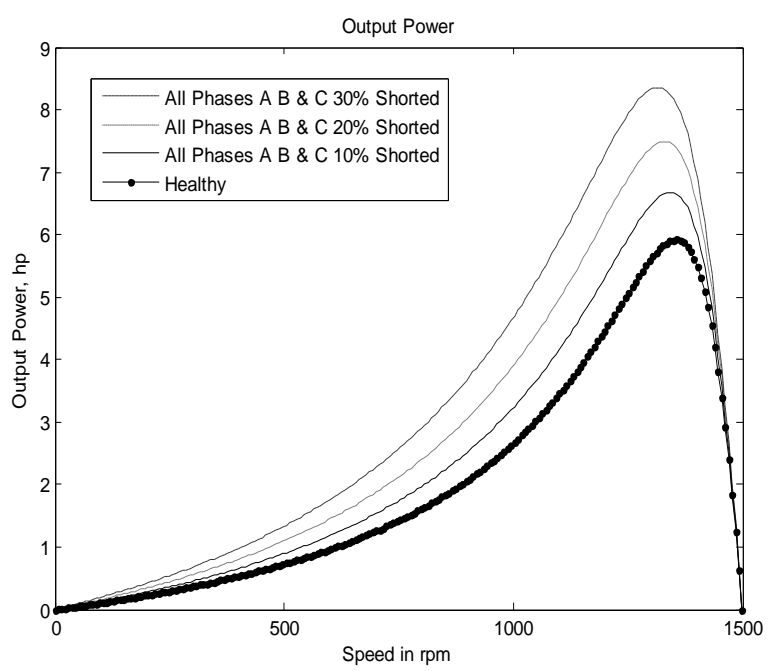

(d) Output Power with respect to speed

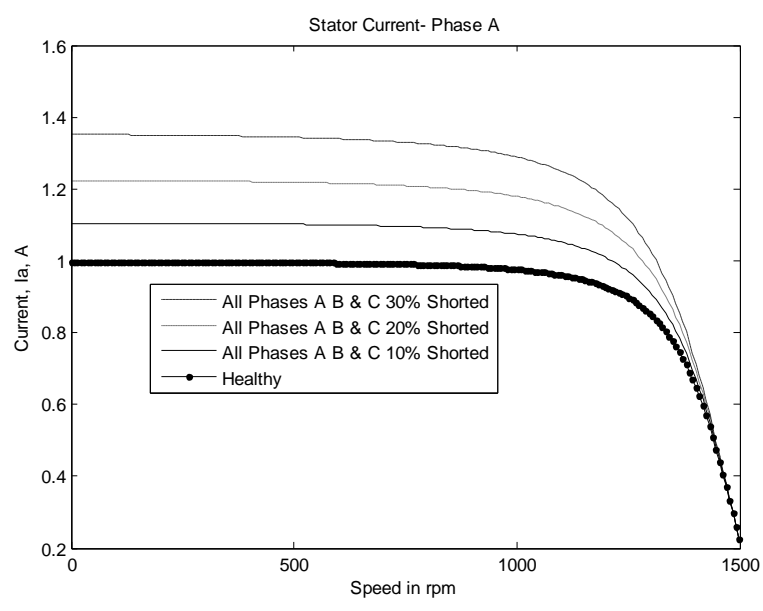

(e) Stator Current of Phase ' $a$ ' with respect to speed

Fig. 10 Effect of a- phase winding which is short circuited by $10 \%, 20 \%, 30 \%, 40 \%$ on motor performance

\section{CONCLUSION}

In this paper, the mathematical mode of TPIM is developed and simulated under different operating conditions. Model is also simulated under one or more stator winding faults such as one, two or three phase windings short circuited by $10 \%$, $20 \%, 30 \%$ and $40 \%$. The performance characteristics of TPIM under healthy and faulty conditions are illustrated. These data may be useful for getting better insight about TPIM and also for the development of soft computing models of TPIM.

\section{REFERENCES}

[1] Tarek I. Haweel (2012), Modeling Induction Motors, International Journal on Electrical Engineering and Informatics - Vol 4 (2), July, pp. 361-370.

[2] Tripti Rai; Prashant Debre (2016), Generalized modeling model of three phase induction motor, International Conference on Energy Efficient Technologies for Sustainability (ICEETS), pp.: 927 931.

[3] Rishabh Verma; Vaskar Sarkar (2016), Accurate modeling of induction motor loads in the load flow analysis of a distribution network, IEEE 6th International Conference on Power Systems (ICPS), pp. $1-5$.

[4] K. T. Chau (2015), Electric Vehicle Machines and Drives: Design, Analysis and Application, Wiley-IEEE Press. 